\title{
Development of Cellulose Acetate Microcapsules with Cyanex 923 for Phenol Removal from Aqueous Media
}

\author{
Irma Pérez-Silva (i), Israel S. Ibarra $(\mathbb{D})$, A. Castañeda-Ovando $(\mathbb{D}$, \\ C. A. Galán-Vidal $(\triangleright$, and Ma. Elena Páez-Hernández \\ Área Académica de Química, Universidad Autónoma del Estado de Hidalgo, Mineral de la Reforma, HGO, Mexico \\ Correspondence should be addressed to Irma Pérez-Silva; ips0901@yahoo.com.mx \\ and Ma. Elena Páez-Hernández; mpaezh@gmail.com
}

Received 29 December 2017; Revised 6 March 2018; Accepted 20 March 2018; Published 23 April 2018

Academic Editor: Josefina Pons

Copyright (C) 2018 Irma Pérez-Silva et al. This is an open access article distributed under the Creative Commons Attribution License, which permits unrestricted use, distribution, and reproduction in any medium, provided the original work is properly cited.

\begin{abstract}
Microcapsules of cellulose acetate with Cyanex 923 were prepared and used in this study for phenol removal from water and synthetic textile wastewater. The influence of several factors on the microcapsules extraction efficiency was studied, as well as characterization and phenol adsorption isotherm. Microcapsules characterization demonstrated the extractant reagent encapsulation, while in a batch mode procedure, good adsorption of phenol (ca. $5.5 \times 10^{-3} \mathrm{~mol} \mathrm{Kg}^{-1}$ ) has been reached. A slight decrease in phenol extraction percentage was obtained when synthetic textile wastewater was used (ca. $4.955 \times 10^{-3} \mathrm{~mol} \mathrm{Kg}^{-1}$ ), although a decrease in color was observed due to dye microcapsule extraction. Results indicate that this method is a promising alternative to conventional phenol removal technologies for aqueous samples of low phenol concentrations or in textile effluents.
\end{abstract}

\section{Introduction}

Cellulose acetate is the most studied and most widely used cellulose ester derivative. It can be obtained through reaction of cellulose and acetic anhydride, in which hydroxyl groups are replaced by acetate groups; the properties of the obtained polymer will depend on the substitution degree [1].

For more than 100 years, cellulose acetate has been part of new materials such as membranes, powders, fibers, hydrogels, beads, and microbeads, the latter in a range of 1-1000 mm. Cellulose particles are also hydrophilic and exhibit a high specific surface area and good swelling properties. Spheres (solid matrix particles) and capsules (hollow reservoir particles) made of cellulose have been used for controlled release and as a sorbent material because they are cheap and innocuous and have excellent physical properties [2]. The versatility of the use of cellulose particles in chemical species sorption lies in the fact that they can be functionalized to make them selective and increase their extracting ability [3].

For cellulose spheres, various publications report their use in the extraction of heavy metals such as lead [4], chromium [5], and cadmium [6]. The sphere preparation process followed strategies such as introducing phosphate ester groups into the cellulose porous sphere [4], mixing cellulose with nanochitosan as a crosslinking agent [7], or grafting vinylbenzyl chloride onto cellulose microspheres followed by amination [5].

In the case of cellulose capsules, as far as we know, there is just one report where capsules are prepared from a magnetic microsphere made of cellulose nanocrystals; the polystyrene microsphere filler is dissolved with acetone, leaving a magnetic shell [8]. Thus, even when there are reports of extractant-filled capsules made with synthetic [9-16] and natural [17] polymers, the preparation and use of cellulose capsules for the removal of chemical species remains an issue that has not been developed.

Considering the above, the purpose of this work is to develop biocapsules made of cellulose acetate for the elimination of phenol. The relevance of the removal of this compound lies in the fact that exposure to phenol levels between 9 and $25 \mathrm{mg} \mathrm{L}^{-1}$ causes health problems, due to their toxic, mutagenic, carcinogenic, and teratogenic effects [18]. Phenol exists In the environment due to the activities of chemical, oil, pharmaceutical, or tinctorial industries and can penetrate ecosystems as a result of drainage off the municipal or industrial sewage to surface water [19]. For this reason, 
numerous methods have been developed for phenol removal, such as biodegradation, chemical, electrochemical, and photocatalytic oxidation, solid phase extraction, ozonation, liquid-liquid extraction, pervaporation, and distillation [20], with some problems such as the generation of secondary pollutants and high energy consumption. This shows the need to develop new green treatments such as the one we are proposing.

Thus, in this work, a cellulose acetate biopolymer was used for the development of microcapsules containing Cyanex 923, a solvating reagent which has proven to be a good phenol extractant in studies on liquid-liquid extraction [21], supported liquid membranes [22, 23], and solvent impregnated resins [24], among others. Variables such as the amount of extractant, $\mathrm{pH}$ of the aqueous solution, extraction time, and reusability were studied during phenol removal experiments. This information was vital to understand the principles that govern the sorption process and for scaling it up to a practical batch system for phenol extraction from synthetic wastewater.

\section{Experimental}

2.1. Materials. Organic reagents, dimethylformamide (DMF), cellulose acetate (CA), sodium dodecyl sulfate, phenol ( $\mathrm{Ph}$ ), and $\mathrm{NaOH}$ were obtained from Aldrich (Sigma-Aldrich, $\mathrm{MO}$; ACS grade). The extractant trialkylphosphine oxide (Cyanex 923) (Cy) was supplied by Cytec Industries Inc. (Hermosillo, Mexico); ethanol and indigo dye were obtained from local stores. Deionized water was obtained from a MilliQ Plus system (Millipore, MA) with a resistivity of $18.2 \mathrm{M} \Omega \mathrm{cm}$ and used for phenol solutions and during the capsules' preparation process.

2.2. Preparation of Cellulose Acetate Microcapsules with Cyanex 923 (CA-MC-Cy). Microcapsules were prepared by the phase inversion precipitation technique as follows: $1.2 \mathrm{~g}$ of CA was dissolved in $15 \mathrm{~mL}$ of DMF; then, different amounts of extractant were added to the CA solution and the resulting mixture was stirred for $15 \mathrm{~min}$ at room temperature. The prepared dispersed phase was then added dropwise to the continuous phase [sodium dodecyl sulfate $(0.5 \% \mathrm{w} / \mathrm{v})$ in an ethanol-water solution (3-10, v/v)] using a syringe with a needle (OD: $0.36 \mathrm{~mm}$ ). Finally, the obtained CA-MC-Cy was washed with deionized water several times and dried at $45^{\circ} \mathrm{C}$ for $24 \mathrm{~h}[12,25]$. Free Cyanex capsules (CA-MC) were made in a similar way but without including the extractant in the preparation process.

2.3. Characterization of CA-MC-Cy. FTIR spectra of the microcapsules with Cyanex were assessed using an FTIR spectrophotometer (PerkinElmer System 2000), performed in the range of $500-4000 \mathrm{~cm}^{-1}$. The CA-MC-Cy morphology was analyzed using scanning electron microscopy (SEM) (JEOL JSM-63000 microscope) (5.0 kV; 22x, 50x, and 500x). Energy dispersive X-ray (EDX) analysis for capsules with and without Cyanex was performed using a scanning electron microscope (SEM) model JEOL JSM-5600LV. To determine the amount of extractant lost during microcapsules preparation, several Cy solutions were prepared in the continuous phase where capsules without an extractant were prepared. Each one of these solutions was analyzed in a PerkinElmer GX Raman FTIR equipped with an Nd:YAG laser (1064 nm) and an InGaAs detector. The intensity of the characteristic band of the phosphine group at $1110 \mathrm{~cm}^{-1}$ was used to construct a calibration curve; with this, the encapsulated amount of Cy (and the one that was lost, by difference) was calculated at several casting Cy solutions.

2.4. Phenol Adsorption Experiments. $50 \mathrm{~mL}$ of phenol aqueous solution $\left(25 \mathrm{mg} \mathrm{L}^{-1}\right)$ was mixed with a weighed amount of CA-MC-Cy for 7 hours. The total Ph sorbed was calculated according to the following equation:

$$
\operatorname{mol}_{\mathrm{Ph}}=1000\left(C_{0}-C_{e}\right) \frac{V}{\mathrm{MW}_{\mathrm{Ph}}},
$$

where $C_{0}$ is the phenol concentration $\left(\mathrm{mg} \mathrm{L}^{-1}\right)$ in the initial solution, $C_{e}$ is the phenol concentration $\left(\mathrm{mg} \mathrm{L}^{-1}\right)$ in the solution at the end of the adsorption experiment, $V$ is the aqueous solution volume (L), and $\mathrm{MW}_{\mathrm{Ph}}$ is phenol molecular weight.

During adsorption experiments, samples were manually taken for phenol spectrophotometric quantification according to Woolard and Irvine [31] in a Lambda $40 \mathrm{UV} / \mathrm{Vis}$ Spectrophotometer (PerkinElmer) at $510 \mathrm{~nm}$.

2.5. Reusability of CA-MC-Cy. For reusability studies, $2 \mathrm{~g}$ of CA-MC-Cy-Ph (obtained after phenol extraction) was placed in a beaker containing $50 \mathrm{~mL}$ of $\mathrm{NaOH}$ at $0.25 \mathrm{~mol} \mathrm{~L}^{-1}$. The mixture was shaken for $15 \mathrm{~h}$ and the Ph-free capsules were washed with deionized water and reused for a new phenol adsorption experiment. This procedure was repeated 4 times. The $\mathrm{Ph}$ concentration in the aqueous solution was determined spectrophotometrically every time as described above.

2.6. Phenol Adsorption from Synthetic Wastewater. In this experiment, wastewater from a textile manufacturer from Hidalgo State (Mexico) was used for phenol solution preparation doped with $\mathrm{NaCl}\left(1 \mathrm{~g} \mathrm{~L}^{-1}\right), \mathrm{Na}_{2} \mathrm{SO}_{4}\left(1 \mathrm{~g} \mathrm{~L}^{-1}\right)$, indigo dye (500 $\mathrm{mg} \mathrm{L}^{-1}$ ), and phenol (25 $\mathrm{mg} \mathrm{L}^{-1}$ ) [32]. The experiment was conducted similarly to those where deionized water was used.

\section{Results and Discussion}

3.1. Characterization of Capsules. Samples of CA-MC and CA-MC-Cy were analyzed using scanning electron microscopy (SEM). According to Figure 1(a), it is possible to observe that microcapsules were not spherical but elliptical. The SEM images of the microcapsules' cross section observed in Figure 1(b) showed the hollow core of the MC and a thin layer thickness of ca. $200 \mu \mathrm{m}$. The diffusion of DMF into the water and the ethanol-water diffusion into the CA polymer solution form the skin capsule, while the 


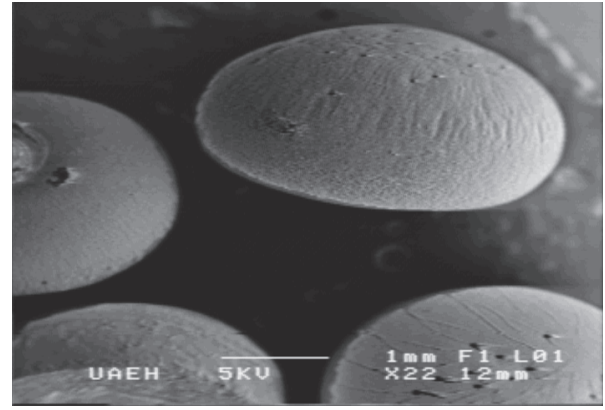

(a)

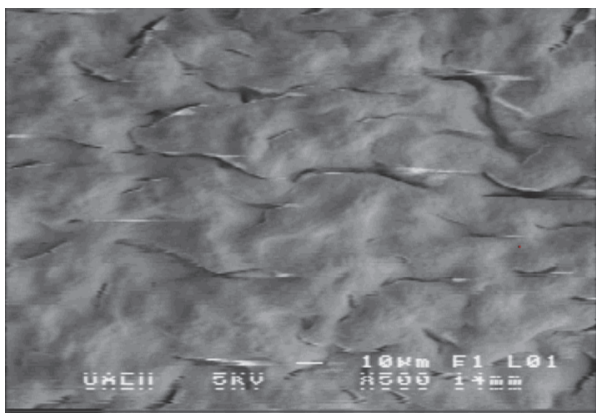

(c)

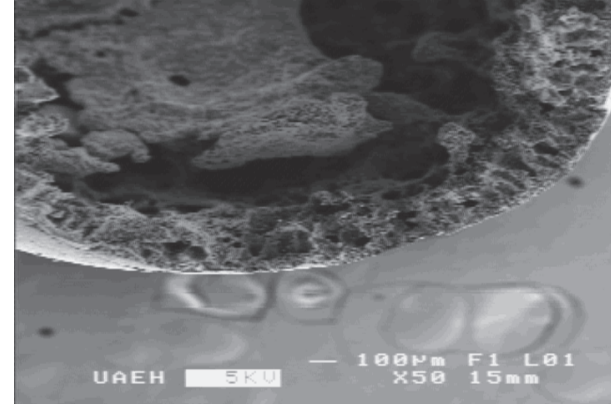

(b)

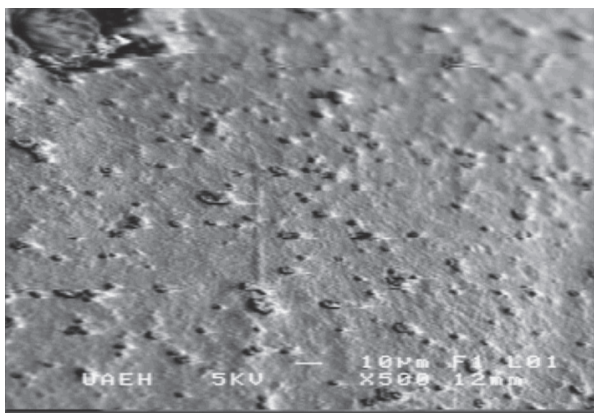

(d)

Figure 1: Scanning electron micrograph for (a) cellulose acetate microcapsules with Cyanex 923 at $1 \mathrm{~mol} \mathrm{~L}^{-1}$ (22x); (b) cross section of CAMC-Cy (50x); (c) cellulose acetate capsules surface (500x); (d) surface of CA-MC-Cy (22x).

hydrophobic Cyanex is trapped inside the capsule during the polymerization process.

CA-MC from Figure 1(c) shows thin wrinkles that originated by the slight shrinkage of the sphere after the drying process. Conversely, the surface of CA-MC-Cy does not look contracted which can be attributed to the humectant action of the Cyanex contained in the capsule (Figure 1(d)). However, small aggregates (nodule structures) may be noticed on the capsule surface [33]; this is a consequence of rapid polymerization due to the increased hydrophobicity of the dispersed phase by Cyanex addition. The above is reflected in the estimated diameter of the microcapsules, being lower in the case of spheres without Cy $(2.05 \mathrm{~mm}, n=8)$ than those prepared with the extractant $(2.28 \mathrm{~mm}, n=8)$.

To confirm the existence of Cyanex 923 in the prepared microcapsules, the infrared spectra of CA-MC, Cyanex 923, and CA-MC-Cy were obtained. In Figure 2(a), Cyanex 923 spectrum shows characteristic peaks: one for phosphine group located at $1148 \mathrm{~cm}^{-1}$ corresponding to the stretching vibration of $\mathrm{P}=\mathrm{O}$ and one more at $1460 \mathrm{~cm}^{-1}$ for the antisymmetric stretching vibration of P-C. Additionally, bands at 2856 and $2925 \mathrm{~cm}^{-1}$ correspond, respectively, to asymmetric and symmetric stretching for $\mathrm{CH}_{2}$ of the alkyl chain [10].

On the other hand, the spectrum from Figure 2(b) shows the typical peaks of cellulose acetate [34]: $1739 \mathrm{~cm}^{-1}(\mathrm{C}=\mathrm{O}$ st.), $1368 \mathrm{~cm}^{-1}$ ( $\mathrm{CH}_{3}$ sym. def.), $1226 \mathrm{~cm}^{-1}$ (C-O st.), and $1031 \mathrm{~cm}^{-1}$ (C-O-C st.).

Bands for Cyanex-cellulose acetate microcapsules at $1157 \mathrm{~cm}^{-1}$ corresponding to $\mathrm{P}=\mathrm{O}$ stretching for phosphine

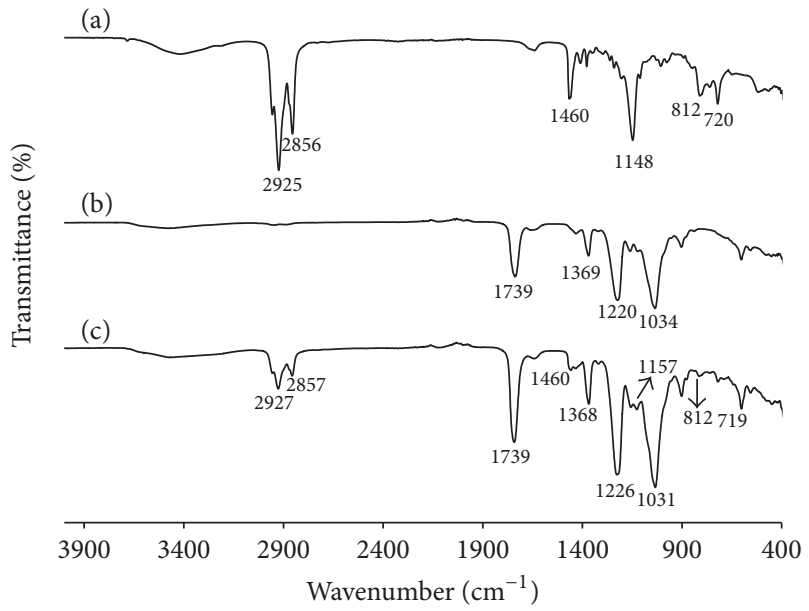

FIgURE 2: Infrared spectrum for (a) Cyanex 923, (b) cellulose acetate microcapsules, and (c) cellulose acetate microcapsules with Cyanex 923 at $1 \mathrm{~mol} \mathrm{~L}^{-1}$.

group and P-C vibration at $1460 \mathrm{~cm}^{-1}$ in Figure 2(c) demonstrate that Cyanex 923 was successfully incorporated into the MC.

Energy dispersive X-ray (EDX) analysis was performed on CA-MC and CA-MC-Cy prepared from several Cy casting solution concentrations. Results showed a $0 \%$ weight percentage of $\mathrm{P}$ for CA-MC and a logarithmic increase for CA-MC-Cy $(3.1,3.6,4.0,6.4$, and 6.3 for MC prepared from 


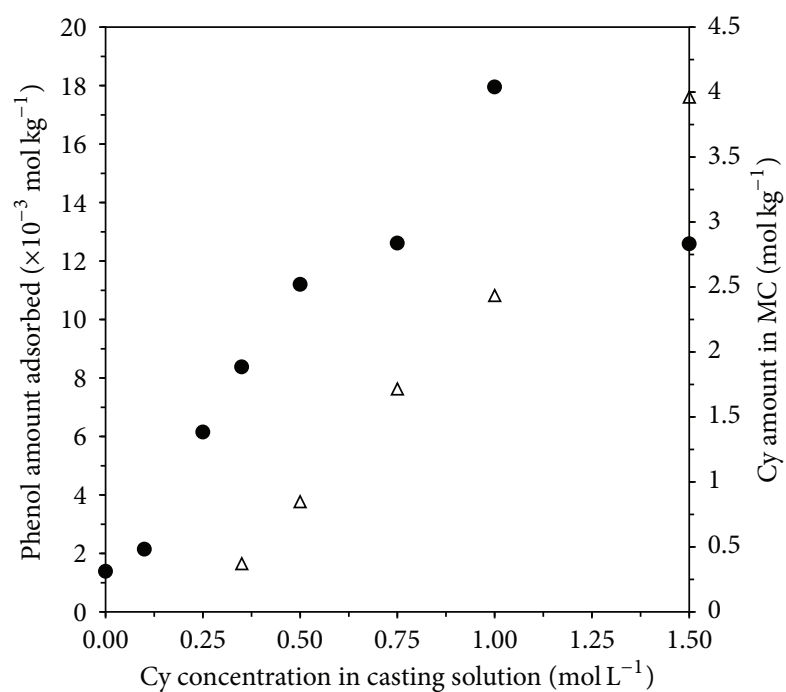

Figure 3: Phenol extraction to CA-MC-Cy prepared with several casting solutions containing different concentrations of Cyanex $923(\bullet)$ and Cy amounts in MC calculated from IR analysis $(\triangle)$. Experimental conditions: $50 \mathrm{~mL}$ of phenol at $25 \mathrm{mg} \mathrm{L}^{-1}(\mathrm{pH}=6)$, $0.25 \mathrm{~g}$ of CA-MC-Cy, 7 hours of experimental time.

$0.1,0.25,0.35,1.00$, and $1.5 \mathrm{~mol}_{\mathrm{Cy}} \mathrm{L}^{-1}$ in casting solutions, resp.).

3.2. Variation of Cyanex 923 Concentration during Capsule Preparation. In order to find the best extractant concentration for phenol sorption, microcapsules were prepared in various solutions at Cyanex concentration in the range from 0 to $1.5 \mathrm{~mol} \mathrm{~L}^{-1}$. The results shown in Figure 3 demonstrate that phenol extraction is due to the presence of Cyanex in capsules since less sorption (ca. $0.1 \mathrm{mg}_{\mathrm{Ph}}$ ) is obtained with CA-MC. This interaction can be described with a 1:1 reaction as follows [23]:

$$
\mathrm{Ph}_{\mathrm{aq}}+\mathrm{Cy}_{\mathrm{MC}} \leftrightarrows \mathrm{Ph} \cdot \mathrm{Cy}_{\mathrm{MC}}
$$

On the other hand, it can be noticed that the sorption capacity of MC increases with the amount of Cyanex 923 used during the capsule preparation; this is a consequence of the more extractant entrapped in the microcapsule due to the higher amount of Cyanex available in the casting solution. In addition to those mentioned in the manuscript, a $2 \mathrm{M}$ Cyanex solution was used to prepare the capsules without success (capsules were not formed). However, it should be said that capsules prepared with Cy $1.5 \mathrm{M}$ casting solution, apparently stable, caused the appearance of turbidity at the end of the extraction experiment as a consequence of the mass release of the MC. This could be the reason why the phenol sorption decreased significantly with MC prepared with $1.5 \mathrm{M}_{\mathrm{Cy}}$ concentration. According to this, the Cyanex concentration value of $1 \mathrm{~mol} \mathrm{~L}^{-1}$ casting solution was selected to carry out the following experiments.
TABLE 1: pH modification of aqueous solutions and its effect on phenol extraction. Experimental conditions: $50 \mathrm{~mL}$ of phenol at $25 \mathrm{mg} \mathrm{L}^{-1}, 0.25 \mathrm{~g}$ of CA-MC-Cy prepared with $1 \mathrm{~mol} \mathrm{~L}^{-1}$ of Cyanex 923, 7 hours of experimental time.

\begin{tabular}{lc}
\hline Solution $\mathrm{pH}$ value & Phenol sorption $\left(\mathrm{mol} \mathrm{Kg}^{-1}\right)^{*}$ \\
\hline 1 & $2.00(3.35)$ \\
3 & $2.10(5.89)$ \\
5 & $2.01(4.10)$ \\
6 & $1.93(3.39)$ \\
11 & $1.59(7.95)$ \\
\hline
\end{tabular}

${ }^{*}$ Relative standard deviation in percentage (\% RSD), $n=3$.

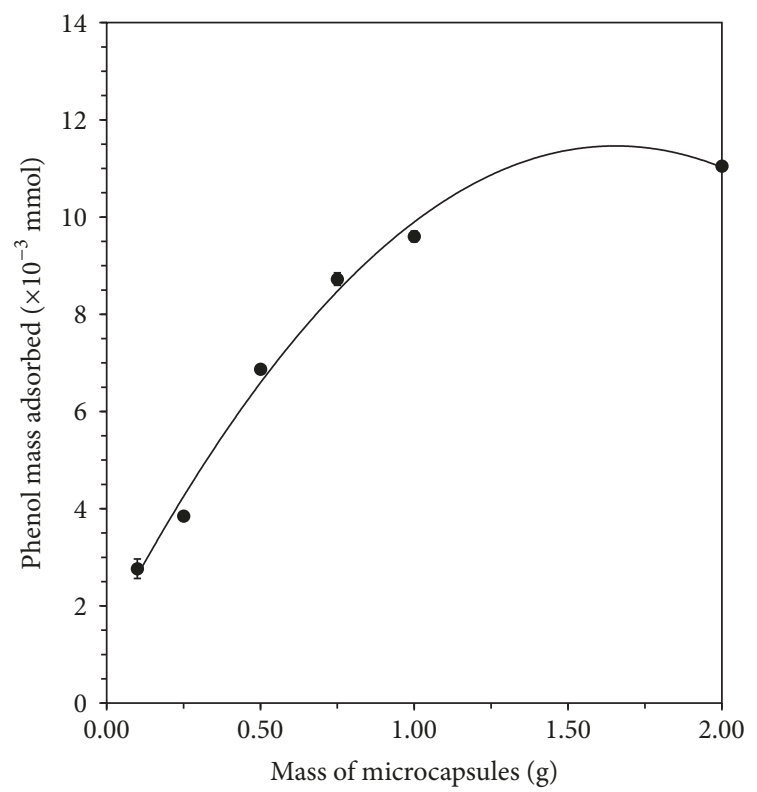

FIGURE 4: Effect of mass of CA-MC-Cy on the phenol extraction from aqueous solutions. Conditions: $50 \mathrm{~mL}$ of phenol at $25 \mathrm{mg} \mathrm{L}^{-1}$ $(\mathrm{pH}=3), 7$ hours of experimental time.

composition, the $\mathrm{pH}$ value of phenol solutions was adjusted in a range from 1 to 11 by the addition of $\mathrm{NaOH}$ or $\mathrm{HCl}$ prior to the sorption step.

Results presented in Table 1 confirm the solvation mechanisms by which phenol is extracted with Cyanex. Thus, a decrease of the phenol sorption occurs at a $\mathrm{pH}$ value of 11 as a consequence of the growing phenol dissociation $\left(\mathrm{pKa}_{\text {Phenol }}=\right.$ 10) [35]. Conversely, there was no significant change in phenol removal at the $\mathrm{pH}$ range from 1 to 6 , for which a $\mathrm{pH}$ value of 3 was chosen for subsequent experiments.

3.4. Effect of CA-MC-Cy Mass. To increase the phenol sorption, the amount of capsules in different sorption experiments was increased from 0.1 to $2 \mathrm{~g}$ (Figure 4). As expected, an increase in the $\mathrm{Ph}$ sorption is observed due to an increase of available sites for the extraction process [36]. Therefore, further experiments were performed with $2 \mathrm{~g}$ of capsules.

3.5. Effect of Contact Time. This study allows evaluating the time at which equilibrium is reached in the extraction 
TABLE 2: Freundlich and Langmuir constants for phenol sorption on CA-MC-Cy. Experimental conditions: $50 \mathrm{~mL}$ of phenol at $25 \mathrm{mg} \mathrm{L} \mathrm{m}^{-1}$ $(\mathrm{pH}=3), 2 \mathrm{~g}$ of CA-MC-Cy prepared with $1 \mathrm{~mol} \mathrm{~L}^{-1}$ of extractant reagent, room temperature.

\begin{tabular}{ccccc}
\hline & Langmuir isotherm & \multicolumn{3}{c}{ Freundlich isotherm } \\
$Q_{o}\left(\mathrm{mg} \mathrm{g}^{-1}\right)$ & $K_{L}\left(\mathrm{~L} \mathrm{mg}^{-1}\right)$ & $R^{2}$ & $K_{F}\left(\mathrm{~L} \mathrm{~g}^{-1}\right)$ & $n_{o}$ \\
\hline 5.74 & 1.77 & 0.953 & 27.28 & 0.58 \\
\hline
\end{tabular}

TABLE 3: Comparison of the phenol adsorption capacity $(q)$ of several adsorbents derived from natural material.

\begin{tabular}{lcc}
\hline Adsorbent material & Phenol adsorption capacity, $q\left(\mathrm{mg} \mathrm{g}^{-1}\right)$ & \multicolumn{1}{c}{ Reference } \\
\hline Coke breeze & 0.18 & [26] \\
Natural zeolite modified with surfactant & 0.7647 (HDTMA) & 1.2977 (BDTDA) \\
(hexadecyltrimethyl ammonium bromide, HDTMA, and & $5.0715\left(23^{\circ} \mathrm{C}\right)$ & 5.74 \\
benzyltetradecyl ammonium chloride, BDTDA) & 7.9 & [27] \\
Vegetable sponge (cylindrical loofa) & 11.175 & This work \\
Cellulose capsules & 16.1 & {$[26]$} \\
Rice husk and rice husk char & {$[29]$} \\
Activated carbon from Terminalia arjuna nut & {$[30]$} \\
Chitin purified powder from shrimp shells & &
\end{tabular}

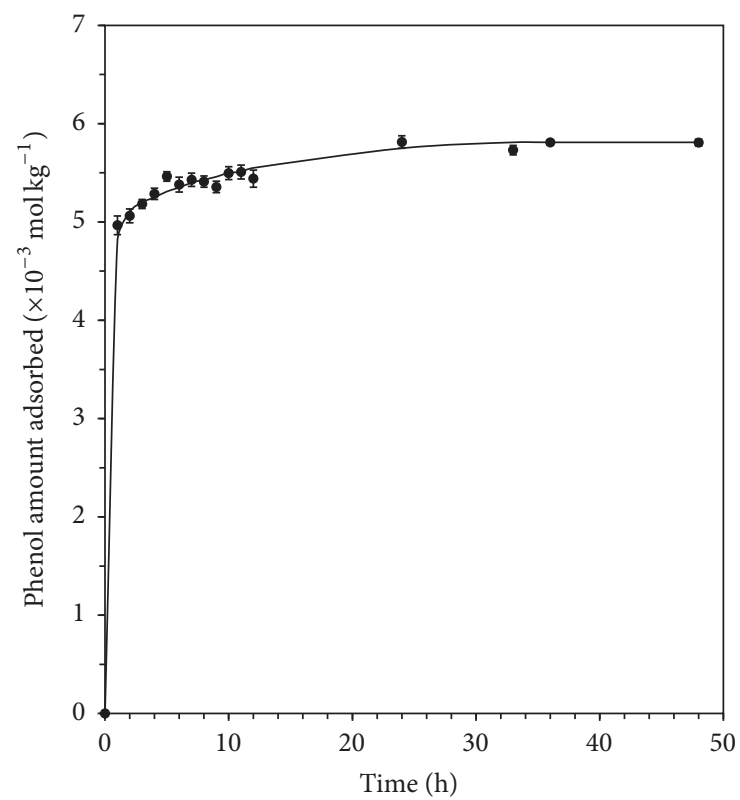

FIGURE 5: Evaluation of contact time in the extraction of phenol with CA-MC-Cy. Experimental conditions: $50 \mathrm{~mL}$ of phenol at $25 \mathrm{mg} \mathrm{L}^{-1}$ $(\mathrm{pH}=3), 2 \mathrm{~g}$ of CA-MC-Cy prepared with $1 \mathrm{~mol} \mathrm{~L}^{-1}$ of Cyanex 923 .

process. The experimental results from Figure 5 show that the adsorption capacity increases over time and that most of the phenol is extracted during the first $5 \mathrm{~h}$, although the equilibrium is reached until 24 hours. Therefore, the contact time in the isotherm study was $48 \mathrm{~h}$, enough for reaching the extraction equilibrium.

In order to establish the best-fit isotherm model, the sorption data varying phenol concentration from 5 to $100 \mathrm{mg} \mathrm{L}^{-1}$ was analyzed using Langmuir and Freundlich equations [37].
According to Table 2, Langmuir's model represents phenol sorption by CA-MC-Cy more adequately than Freundlich model. Thus, this process is characterized by having uniform adsorption energies on the surface, where there is no transmigration of the adsorbate. On the other hand, $R_{L}$ values confirm the suitability of the use of CA-MC-Cy for phenol recovery since its values range between 0.006 and 0.113 [38].

According to the results, the obtained quantity of Cy in the CA-MC-Cy (Figure 3) exceeds the maximum sorption capacity predicted by Langmuir ( 0.06 in $\mathrm{mol}_{\mathrm{Ph}} \mathrm{kg}^{-1}$ ) which can be attributed to the fact that as the adsorption process happens, the possibility of finding the available active sites is lower since it gradually carries out surface coverage. The above agrees with the data obtained in Section 3.2 (amount of $\mathrm{Cy}$ in the MC), since in all cases there is an excess of the extractant agent regarding the amount of $\mathrm{Ph}$ present in the solution without having good percentages of adsorption in all cases. This difference may probably be due to the use of low concentration solutions (diluted) or because of the difficulties in the Ph-Cy interaction, which agrees with the low equilibrium constant $\left(1.05 \times 10^{3} \mathrm{~m}^{3} \mathrm{Kmol}^{-1}\right)$ [22]

It is important to note that the sorption capacity calculated by Langmuir for CA-MC-Cy is not high; however, it remains competitive compared to other biodegradable adsorbents derived from natural materials used for the removal of phenol (Table 3).

3.6. Regeneration and Reuse of the Microcapsules. The reuse capacity of the CA-MC-Cy is an important feature that could describe the stability and durability of the microcapsules. To carry out this process, CA-MC-Cy-Ph must first be regenerated by removing the contained phenol using alkaline solutions to form phenolate which is not retained by Cyanex $[22,23,35]$. Afterwards, the regenerated CA-MC-Cy was used again for phenol extraction in several cycles. 


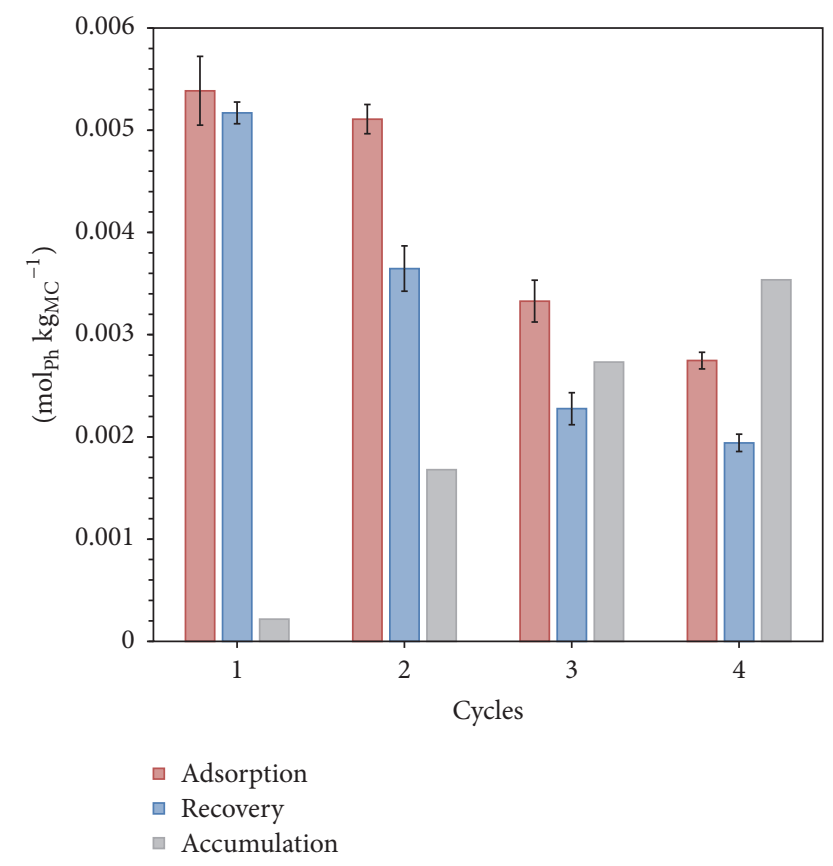

FIGURE 6: Reusability studies of CA-MC-Cy for phenol extraction. Experimental conditions for the extraction step: $50 \mathrm{~mL}$ of phenol at $25 \mathrm{mg} \mathrm{L}^{-1}(\mathrm{pH}=3), 2 \mathrm{~g}$ of CA-MC-Cy prepared with $1 \mathrm{~mol} \mathrm{~L}^{-1}$ of extractant reagent. Experimental conditions for the recovery step: $2 \mathrm{~g}$ of CA-MC-Cy-Ph and $50 \mathrm{~mL}$ of $\mathrm{NaOH} 0.25 \mathrm{~mol} \mathrm{~L}^{-1}, 24 \mathrm{~h}$ of contact time.

Although reextraction of phenol remains constant in the last cycles, Figure 6 shows that phenol extraction capacity of CA-MC-Cy decreases after the second cycle. This suggests that the regeneration process with alkaline solutions causes a significant Cyanex loss due to the emulsification processes of the extractant in the $\mathrm{NaOH}$ aqueous medium [39].

In spite of the above, the use of the prepared capsules presents important benefits in comparison with other sorbent materials, as it is a biodegradable and inexpensive material (30\$ per gram of CA-MC-Cy). Nevertheless, it could be possible to increase the stability of CA-MC by coating the capsules with another polymer or by using a crosslinker. This can be an alternative to improve the poor stability that biopolymers generally have $[40,41]$.

3.7. Phenol Extraction from Synthetic Wastewater. This study was conducted by doping wastewater from a textile manufacturer from Hidalgo State (Mexico) [32]. Phenol sorption was $4.95 \times 10^{-3} \mathrm{~mol} \mathrm{Kg}^{-1} \pm 0.9 \%$, around 15 percent less than that obtained with solutions prepared with deionized water. However, it is important to note that the extraction of the dye was also registered, which could have a negative impact on the extraction of the phenol.

\section{Conclusions}

Cellulose acetate microcapsules with immobilized Cyanex 923 were successfully prepared by means of phase inversion method for phenol removal from water and synthetic solutions. Phenol sorption of $5.5 \times 10^{-3} \mathrm{~mol} \mathrm{Kg}^{-1}$ was obtained under optimal conditions: $2 \mathrm{~g}$ of CA-MC-Cy impregnated with $1 \mathrm{~mol} \mathrm{~L}^{-1}$ of Cyanex 923 and $50 \mathrm{~mL}$ of phenol aqueous solution at $25 \mathrm{mg} \mathrm{L}^{-1}$ at $\mathrm{pH} 3$.

The phenol contained in the developed microcapsules can be removed with a solution of sodium hydroxide. However, studies showed that this can leach the encapsulated extractant. In order to be able to reuse the MCs, the concentration of Cyanex used to prepare the microcapsules could be increased, or an extractant insoluble in basic media can be used.

The principal advantages of the developed CA-MC-Cy include its low cost and easy synthesis, besides being made with a biopolymer. Additionally, the microspheres elaborated in this study allow the phenol removal even from complex solutions such as wastewater from textile industries. These characteristics suggest that these microcapsules have a high potential for application in the removal of pollutants present in environmental aqueous samples.

\section{Conflicts of Interest}

The authors declare that there are no conflicts of interest regarding the publication of this paper.

\section{Acknowledgments}

Irma Pérez-Silva, Ma. Elena Páez-Hernández, C. A. GalánVidal, A. Castañeda-Ovando, and Israel S. Ibarra would like to gratefully thank the SNI for the distinction of their membership.

\section{References}

[1] M. C. Goncalves and M. M. Favaro Ferrarezi, "Recent Developments in Cellulose and Cellulose Derivatives/Clay Nanocomposites," in Handbook of Polymer nanocomposites. Processing, Performance and Application, J. K. Pandey, K. R. Reddy, A. K. Mohanty, and M. Misra, Eds., Springer, London, England, 2014.

[2] S. Fischer, K. Thümmler, B. Volkert, K. Hettrich, I. Schmidt, and K. Fischer, "Properties and applications of cellulose acetate," Macromolecular Symposia, vol. 262, no. 1, pp. 89-96, 2008.

[3] J. Schaller, F. Meister, T. Schulze, and M. Krieg, "Novel absorbing fibres based on cellulose acetate," Lenzinger Berichte, vol. 91, pp. 77-83, 2013.

[4] X. Ma, C. Liu, D. P. Anderson, and P. R. Chang, "Porous cellulose spheres: Preparation, modification and adsorption properties," Chemosphere, vol. 165, pp. 399-408, 2016.

[5] T. Yu, S. Liu, M. Xu, J. Peng, J. Li, and M. Zhai, "Synthesis of novel aminated cellulose microsphere adsorbent for efficient Cr(VI) removal," Radiation Physics and Chemistry, vol. 125, pp. 94-101, 2016.

[6] S. Hokkanen, E. Repo, L. J. Westholm, S. Lou, T. Sainio, and M. Sillanpää, "Adsorption of $\mathrm{Ni2}+, \mathrm{Cd} 2+, \mathrm{PO} 43$ - and NO3- from aqueous solutions by nanostructured microfibrillated cellulose modified with carbonated hydroxyapatite," Chemical Engineering Journal, vol. 252, pp. 64-74, 2014.

[7] K. Vijayalakshmi, B. M. Devi, S. Latha et al., "Batch adsorption and desorption studies on the removal of lead (II) from aqueous solution using nanochitosan/sodium alginate/microcrystalline 
cellulose beads," International Journal of Biological Macromolecules, vol. 104, pp. 1483-1494, 2017.

[8] T. Nypelö, C. Rodriguez-Abreu, Y. V. Kolena'ko, J. Rivas, and O. J. Rojas, "Microbeads and hollow microcapsules obtained by self-assembly of pickering magneto-responsive cellulose nanocrystals," ACS Applied Materials \& Interfaces, vol. 6, no. 19, pp. 16851-16858, 2014.

[9] T. Gumí and B. Peña, "State of the art of polysulfone microcapsules," Current Organic Chemistry, vol. 17, no. 1, pp. 22-29, 2013.

[10] S. Ozcan, A. Tor, and M. E. Aydin, "Removal of Cr(VI) from aqueous solution by polysulfone microcapsules containing Cyanex 923 as extraction reagent," Desalination, vol. 259, no. 1-3, pp. 179-186, 2010.

[11] N. A. Ochoa, C. Illanes, J. Marchese, C. Basualto, and F. Valenzuela, "Preparation and characterization of polymeric microspheres for $\mathrm{Cr}(\mathrm{VI})$ extraction," Separation and Purification Technology, vol. 52, no. 1, pp. 39-45, 2006.

[12] W. W. Yang, G. S. Luo, F. Y. Wu, F. Chen, and X. C. Gong, "Di2-ethylhexyl phosphoric acid immobilization with polysulfone microcapsules," Reactive and Functional Polymers, vol. 61, no. 1, pp. 91-99, 2004.

[13] M. F. Bari, M. S. Hossain, I. M. Mujtaba, S. B. Jamaluddin, and K. Hussin, "Simultaneous extraction and separation of $\mathrm{Cu}(\mathrm{II})$, $\mathrm{Zn}(\mathrm{II}), \mathrm{Fe}(\mathrm{III})$ and $\mathrm{Ni}(\mathrm{II})$ by polystyrene microcapsules coated with Cyanex 272," Hydrometallurgy, vol. 95, no. 3-4, pp. 308-315, 2009.

[14] G. Barassi, A. Valdés, C. Araneda et al., "Cr(VI) sorption behavior from aqueous solutions onto polymeric microcapsules containing a long-chain quaternary ammonium salt: Kinetics and thermodynamics analysis," Journal of Hazardous Materials, vol. 172, no. 1, pp. 262-268, 2009.

[15] O. Kazak, A. Tor, I. Akin, and G. Arslan, "Preparation of new polysulfone capsules containing Cyanex 272 and their properties for $\mathrm{Co}$ (II) removal from aqueous solution," Journal of Environmental Chemical Engineering (JECE), vol. 3, no. 3, pp. 1654-1661, 2015.

[16] S. Nishihama, N. Sakaguchi, T. Hirai, and I. Komasawa, "Extraction and separation of rare earth metals using microcapsules containing bis(2-ethylhexyl)phosphinic acid," Hydrometallurgy, vol. 64, no. 1, pp. 35-42, 2002.

[17] W. Wei, D. H. K. Reddy, J. K. Bediako, and Y.-S. Yun, "Aliquat336-impregnated alginate capsule as a green sorbent for selective recovery of gold from metal mixtures," Chemical Engineering Journal, vol. 289, pp. 413-422, 2016.

[18] S. J. Kulkarni and J. P. Kaware, "A review on health effects of phenol," International Journal of Research, vol. 2, no. 5, pp. 968973, 2015.

[19] J. Michałowicz and W. Duda, "Phenols: sources and toxicity," Polish Journal of Environmental Studies, vol. 16, no. 3, pp. 347362, 2007.

[20] L. G. Villegas, N. Mashhadi, M. Chen, D. Mukherjee, K. E. Taylor, and N. Biswas, "A Short Review of Techniques for Phenol Removal from Wastewater," Current Pollution Reports, vol. 2, no. 3, pp. 157-167, 2016.

[21] B. Burghoff and A. B. de Haan, "Liquid-Liquid equilibrium study of phenol extraction with Cyanex 923," Separation Science and Technology, vol. 44, no. 8, pp. 1753-1771, 2009.

[22] M. T. A. Reis, O. M. F. de Freitas, M. R. C. Ismael, and J. M. R. Carvalho, "Recovery of phenol from aqueous solutions using liquid membranes with Cyanex 923," Journal of Membrane Science, vol. 305, no. 1-2, pp. 313-324, 2007.
[23] W. Cichy, S. Schlosser, and J. Szymanowski, "Recovery of phenol with cyanex ${ }^{\circledR} 923$ in membrane extraction-stripping systems," Solvent Extraction and Ion Exchange, vol. 19, no. 5, pp. 905-923, 2001.

[24] B. Burghoff, E. Zondervan, and A. B. de Haan, "Phenol extraction with Cyanex 923: Kinetics of the solvent impregnated resin application," Reactive and Functional Polymers, vol. 69, no. 4, pp. 264-271, 2009.

[25] X. C. Gong, G. S. Luo, W. W. Yang, and F. Y. Wu, "Separation of organic acids by newly developed polysulfone microcapsules containing triotylamine," Separation and Purification Technology, vol. 48, no. 3, pp. 235-243, 2006.

[26] M. Ahmaruzzaman and D. K. Sharma, "Adsorption of phenols from wastewater," Journal of Colloid and Interface Science, vol. 287, no. 1, pp. 14-24, 2005.

[27] A. Kuleyin, "Removal of phenol and 4-chlorophenol by surfactant-modified natural zeolite," Journal of Hazardous Materials, vol. 144, no. 1-2, pp. 307-315, 2007.

[28] H. Cherifi, S. Hanini, and F. Bentahar, "Adsorption of phenol from wastewater using vegetal cords as a new adsorbent," Desalination, vol. 244, no. 1-3, pp. 177-187, 2009.

[29] K. Mohanty, M. Jha, B. C. Meikap, and M. N. Biswas, "Preparation and characterization of activated carbons from Terminalia Arjuna nut with zinc chloride activation for the removal of phenol from wastewater," Industrial \& Engineering Chemistry Research, vol. 44, no. 11, pp. 4128-4138, 2005.

[30] G. Pigatto, A. Lodi, E. Finocchio, M. S. A. Palma, and A. Converti, "Chitin as biosorbent for phenol removal from aqueous solution: Equilibrium, kinetic and thermodynamic studies," Chemical Engineering and Processing: Process Intensification, vol. 70, pp. 131-139, 2013.

[31] C. R. Woolard and R. L. Irvine, "Treatment of hypersaline wastewater in the sequencing batch reactor," Water Research, vol. 29, no. 4, pp. 1159-1168, 1995.

[32] A. Zilly, J. da Silva Coelho-Moreira, A. Bracht et al., "Influence of $\mathrm{NaCl}$ and $\mathrm{Na} 2 \mathrm{SO} 4$ on the kinetics and dye decolorization ability of crude laccase from Ganoderma lucidum," International Biodeterioration \& Biodegradation, vol. 65, no. 2, pp. 340344,2011

[33] I. M. Wienk, R. M. Boom, M. A. M. Beerlage, A. M. W. Bulte, C. A. Smolders, and H. Strathmann, "Recent advances in the formation of phase inversion membranes made from amorphous or semi-crystalline polymers," Journal of Membrane Science, vol. 113, no. 2, pp. 361-371, 1996.

[34] C. Tsioptsias, K. G. Sakellariou, I. Tsivintzelis, L. Papadopoulou, and C. Panayiotou, "Preparation and characterization of cellulose acetate-Fe2O3 composite nanofibrous materials," Carbohydrate Polymers, vol. 81, no. 4, pp. 925-930, 2010.

[35] Y. Park, A. H. P. Skelland, L. J. Forney, and J.-H. Kim, "Removal of phenol and substituted phenols by newly developed emulsion liquid membrane process," Water Research, vol. 40, no. 9, pp. 1763-1772, 2006.

[36] M. K. Jha, N. Van Nguyen, J.-C. Lee, J. Jeong, and J.-M. Yoo, "Adsorption of copper from the sulphate solution of low copper contents using the cationic resin Amberlite IR 120," Journal of Hazardous Materials, vol. 164, no. 2-3, pp. 948-953, 2009.

[37] O. Hamdaoui and E. Naffrechoux, "Modeling of adsorption isotherms of phenol and chlorophenols onto granular activated carbon. Part I. Two-parameter models and equations allowing determination of thermodynamic parameters," Journal of Hazardous Materials, vol. 147, no. 1-2, pp. 381-394, 2007. 
[38] Y. Yuan, J. Liu, B. Zhou, S. Yao, H. Li, and W. Xu, "Synthesis of coated solvent impregnated resin for the adsorption of indium (III)," Hydrometallurgy, vol. 101, no. 3-4, pp. 148-155, 2010.

[39] B. Burghoff, E. L. V. Goetheer, and A. B. de Haan, "Solvent impregnated resins for the removal of low concentration phenol from water," Reactive and Functional Polymers, vol. 68, no. 9, pp. 1314-1324, 2008.

[40] G. Simó, E. Fernández-Fernández, J. Vila-Crespo, V. Ruipérez, and J. M. Rodríguez-Nogales, "Research progress in coating techniques of alginate gel polymer for cell encapsulation," Carbohydrate Polymers, vol. 170, pp. 1-14, 2017.

[41] N. Angelova and D. Hunkeler, "Permeability and stability of chitosan-based capsules: Effect of preparation," International Journal of Pharmaceutics, vol. 242, no. 1-2, pp. 229-232, 2002. 

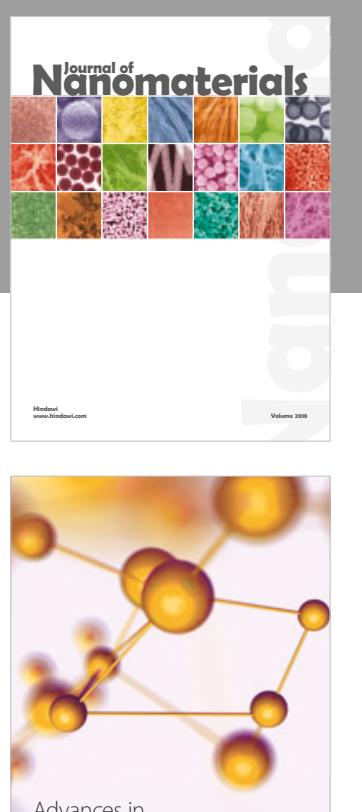

Physical Chemistry
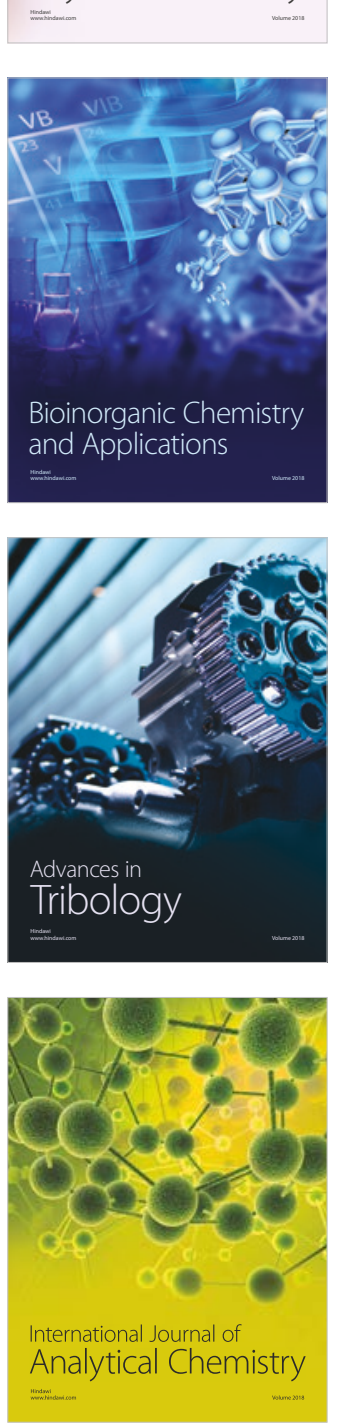

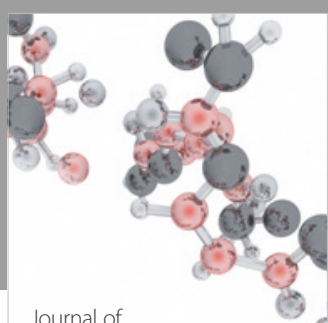

Analytical Methods

in Chemistry

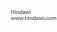

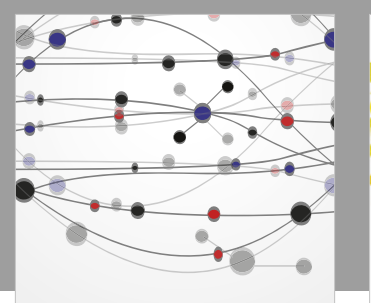

The Scientific World Journal

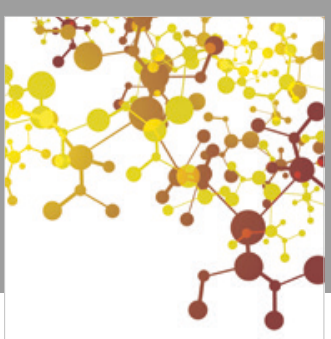

Journal of

Applied Chemistry
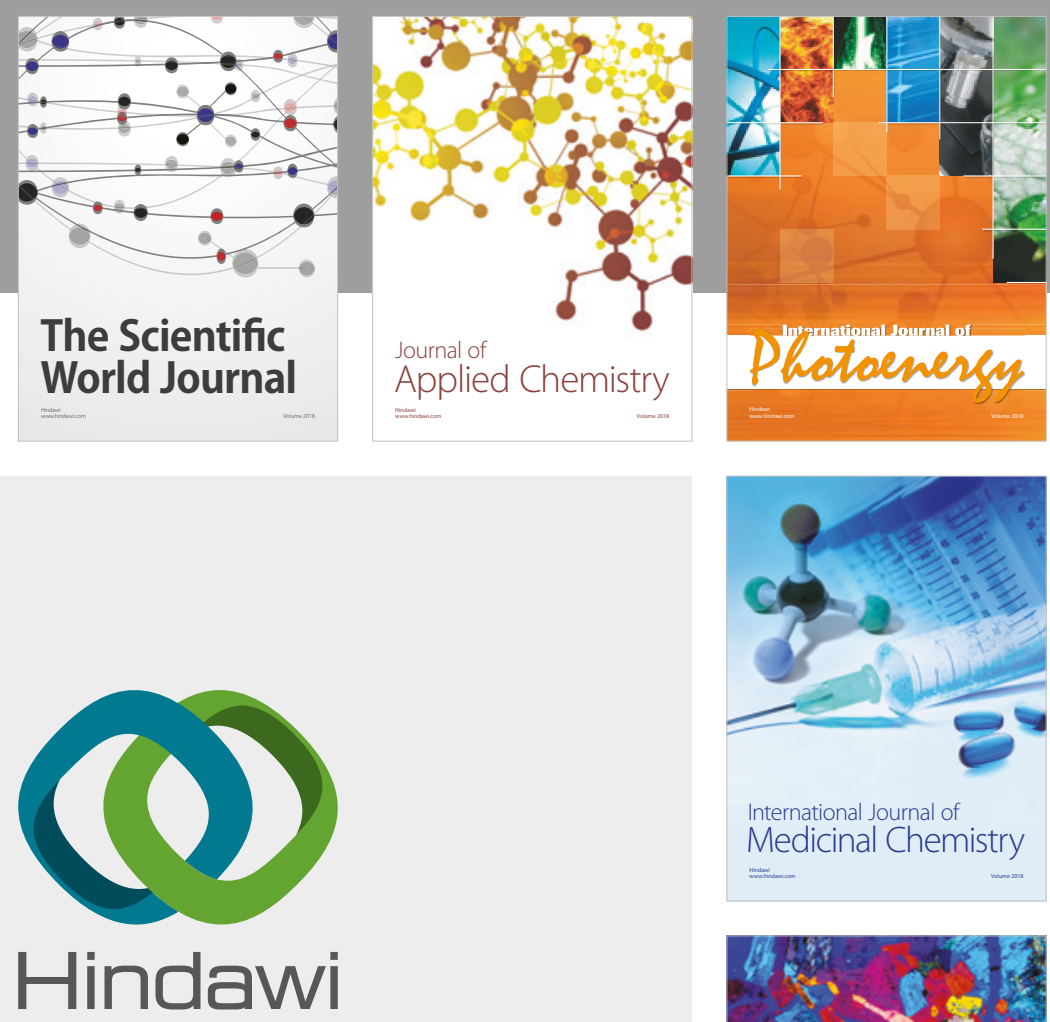

Submit your manuscripts at

www.hindawi.com
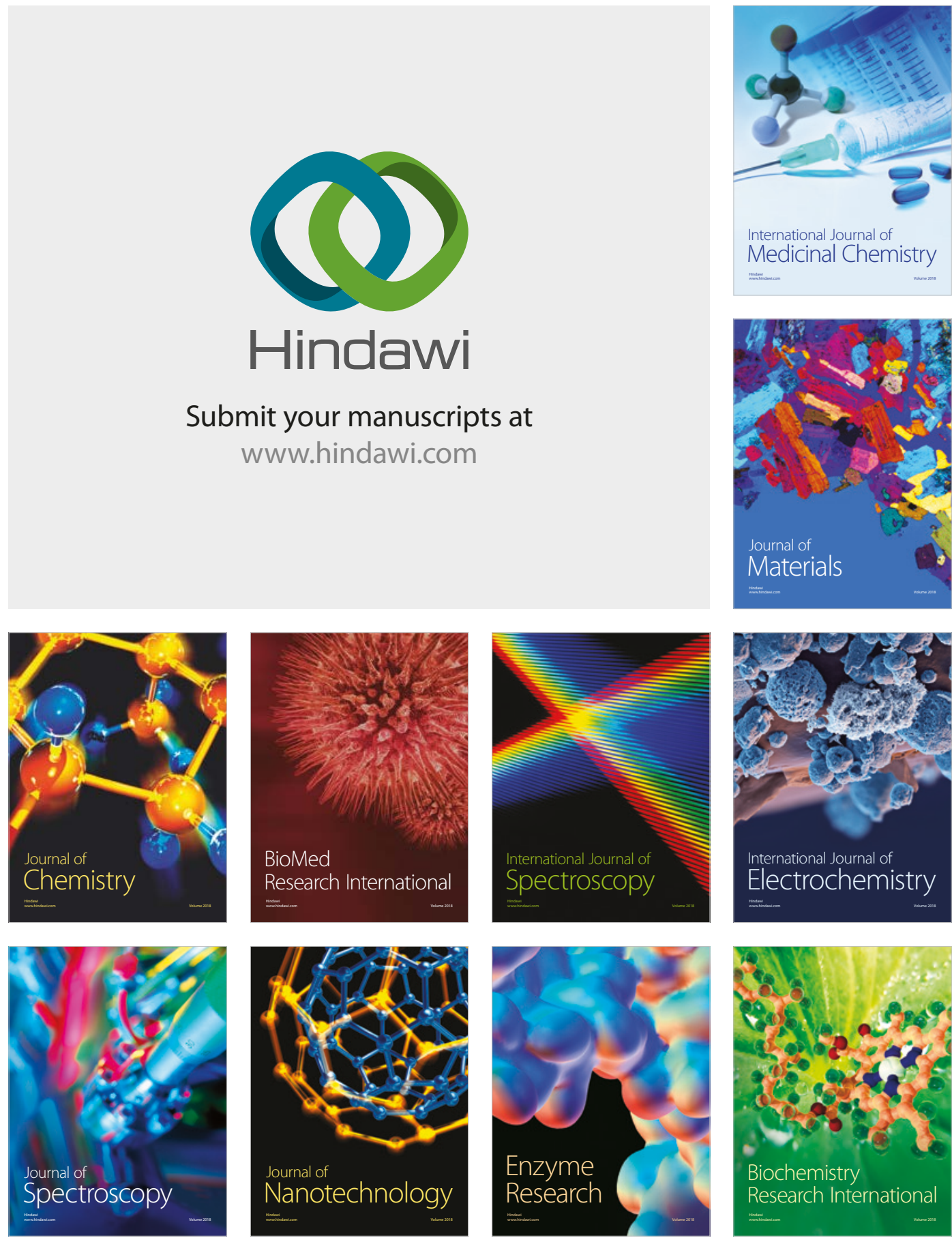
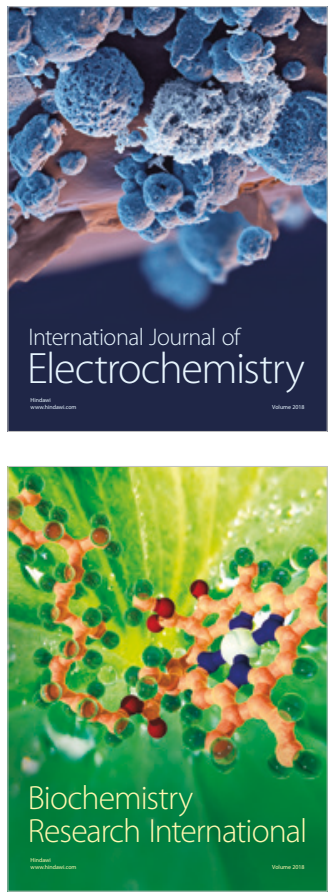